\title{
Are Truckers Being over Stigmatized as HIV Carriers in India? Evidences from Behavioral and Biological Cross-Sectional Surveys among Clients of Female Sex Workers
}

\author{
Damodar Sahu1, Sowmya Ramesh2, Ram Manohar Mishra2*, K. Srikanth Reddy1, \\ Reena Bharadwaj1, Niranjan Saggurti2 ${ }^{2}$, Arvind Pandey', Mandar Mainkar ${ }^{3}$, Bitra George 4 \\ ${ }^{1}$ National Institute of Medical Statistics, ICMR, New Delhi, India \\ ${ }^{2}$ Population Council, New Delhi, India \\ ${ }^{3}$ National AIDS Research Institute, Pune, India \\ ${ }^{4}$ FAMILY Health International, New Delhi, India \\ Email: rammanohar7@yahoo.co.in
}

Received 1 January 2015; accepted 7 March 2015; published 11 March 2015

Copyright (C) 2015 by authors and Scientific Research Publishing Inc.

This work is licensed under the Creative Commons Attribution International License (CC BY).

http://creativecommons.org/licenses/by/4.0/

\section{(c) (i) Open Access}

\section{Abstract}

This paper examines whether truckers have been over-stigmatized as HIV carriers in the country. Data were taken from cross-sectional surveys of clients of female sex workers conducted in 20062007 in 12 districts of the country. A total 4822 clients of female sex workers were covered in the survey. Low-income skilled/semi-skilled men, including non-agricultural/casual labor, and petty businessmen/small shop owners, have the largest share in the clients' population. There was no significant difference between truckers and other sub-group of clients' population in terms of consistent condom use with female sex workers and prevalence of HIV or STI. These evidences suggest that the contribution of truckers in HIV epidemic in India might to similar to other sub-groups of clients' population. Thus, truckers might have been over-stigmatized as HIV carriers in the country. However, there is no doubt that truckers constitute an extremely important target group for the HIV prevention programs and these efforts must be continued to prevent new HIV infections in the country.

\footnotetext{
${ }^{*}$ Corresponding author.
}

How to cite this paper: Sahu, D., Ramesh, S., Mishra, R.M., Reddy, K.S., Bharadwaj, R., Saggurti, N., Pandey, A., Mainkar, M., and George, B. (2015) Are Truckers Being over Stigmatized as HIV Carriers in India? Evidences from Behavioral and Biological Cross-Sectional Surveys among Clients of Female Sex Workers. Open Journal of Preventive Medicine, 5, 85-91. 


\section{Keywords}

\section{Clients, Truckers, Sex Workers, India}

\section{Introduction}

Bridge populations such as truckers and migrant labors are considered to be at risk of contracting HIV in many parts of the world. The high-risk behavior of bridge populations has been associated with the spread of sexually transmitted infection (STI) and HIV in India and elsewhere [1]-[8]. In India, bridge populations are often clients of sex workers and reports indicate that close to 36\% of truckers are clients of sex workers and $15 \%-20 \%$ of clients are truckers [9]. In India, studies reported high-risk behaviors of truckers including sex with multiple partners and low condom use by truck drivers with sex workers (58\% - 74\%) and unpaid female sex partners (20\%) [4] [5] [10]-[14]. Due to their high-risk behavior, truckers particularly those who travel on National Highways for long distances across the country, have attracted researchers and policy makers for their role in disseminating infection from core groups to general population [4] [9] [15]. This is reflected in empirical studies on truckers' sexual behavior and high STI/HIV prevalence in this group. For these reasons, truckers are considered an important bridge group to work with to slow the spread of HIV into the general population [9] [16].

In this context, HIV prevention programs in India have focused on about 5 million long-distance truckers plying on the 3.3 million kilometers of road networks across the country. Although truckers constitute a smaller share than migrants of the bridge population, they are considered to be the most crucial HIV carriers in the country and hence targeted in the national HIV/AIDS prevention program [4] [9] [17].

While many studies in India and globally have explored the risk taking behaviors of trucker drivers and helpers, a comparative analysis of truckers and other clients who visit sex workers is somewhat limited. This paper compares the sexual behavior, HIV, sexual transmitted infection (STI) and therefore the relative contribution of trucker clients (that is, truckers who are clients of female sex workers) and non-trucker clients (that is, all remaining clients of female sex workers) to the Indian epidemic. Hence, this paper examines whether truckers have been over-stigmatized as HIV carriers in the country.

\section{Methodology}

\subsection{Data}

We used data from the Integrated Behavioral and Biological Assessment (IBBA)—a large-scale survey conducted among clients of female sex workers and truckers in India. The cross-sectional survey for clients of FSWs was carried out between October 2006 and June 2007 in 12 districts in three high HIV prevalence Indian states: Andhra Pradesh, Maharashtra, and Tamil Nadu. The IBBA among long-distance truck drivers was conducted between June 2007 and September 2007 at six transshipment locations covering the bulk of India’s transport volume.

Time-location cluster sampling was used for different solicitation site to select respondents [19]. A total 4822 clients of female sex workers and 2066 long distance truckers were covered in the survey. A pre-tested, precoded structure questionnaire for clients was translated into local languages (Hindi, Kannada, Marathi, Tamil and Telugu). A face-to-face interview was to collect information on socio-demographic characteristics, mobility, sexual history, condom use with different partners, history of STI, knowledge of HIV and its prevention, and exposure to HIV prevention interventions. Blood and urine samples were collected from the respondents by trained lab technicians. Blood samples were taken to test for HIV, syphilis and Herpes simplex virus type 2 (HSV-2 in 10\% of samples) using standard serological test and urine sample were taken to test for Neisseria Gonorrhea and Chlamydia trachomatis infection. All respondents were taken to a private setting away from the solicitation site for interviews and biological sample collection. More details about the survey are available elsewhere [5] [18] [19].

\subsection{Measures}

Four occupational groups of clients of female sex workers were created: trucker clients (clients of female sex 
workers who were truck drivers); other transport workers (clients who were helpers/cleaners, rickshaw/taxi/bus drivers); unskilled/semiskilled men (non-agricultural labors/casual labors/petty shop owners/skilled/semiskilled workers); and remaining clients (students, unemployed, domestic servants, businessmen, those in the service sector).

Four types of sexual partners were defined: paid female partners (female partners to whom respondent had paid cash in exchange for sex); non-paid female partners (female partners (other than main/steady partner) with whom respondent had sex with and did not pay), regular female partners (main/steady female partners) and male/transgender partners.

Prevalence of the following four STIs was considered: Syphilis, N. gonorrhea, C. trachomatis and HIV. Any STI was defined as the presence of at least one of the four above said STIs. As HSV-2 was tested only among $10 \%$ of the subsample, it has not been considered in the analysis. A respondent was termed as HIV-positive if he tested positive either for HIV-1 or HIV-2 or both.

The socio-demographic characteristics considered in this study include age (in completed years), literacy (the ability to both read and write), and sexual partnership status (currently married-living with partner; currently married-living alone; not currently married-living with partner; not currently married-living alone).

\subsection{Analysis}

Basic descriptive statistics (i.e., proportions, means and standard deviations) were presented to describe sociodemographic characteristics and sexual behaviors and prevalence of STI and HIV by clients' occupational groups. In the bivariate analyses, chi-square tests were used to assess associations between occupational groups and socio-demographic characteristics, sexual behavior and HIV/STI prevalence. Adjusted odds ratios (adjusted OR) and their 95\% confidence intervals (CI) were derived by using multivariate logistic regression models to examine the independent association of occupational categories with HIV and STI status and consistent condom use with female sex workers. In multivariate analyses, we controlled for the socio-demographic characteristics. Analyses were conducted using STATA software (version 13.0).

\section{Ethical Statement}

All participants in this study provided prior written informed consent. The IBBA protocol and ethical clearances were obtained from the Protection of Human Subjects Committee of FHI 360, and the Health Ministry Screening Committee of Indian Council of Medical Research (ICMR) and local ethical committees of the implementing institutes of ICMR: National AIDS Research Institute, Pune; National Institute of Medical Statistics, New Delhi; National Institute of Nutrition, Hyderabad; and National Institute of Epidemiology, Chennai [20].

\section{Results}

Of a total of 4821 respondents who were clients of female sex workers, $6.4 \%$ were truckers, $7.1 \%$ were other transport workers, $53.4 \%$ were skilled/semiskilled workers and $33.1 \%$ were other clients.

\subsection{Social-Demographic Characteristics}

Table 1 represents the socio-demographic characteristics of clients by occupational groups. The average age of clients was 30 years and no significant difference in age of clients was noticed $(P=0.25)$. However, a larger proportion of trucker clients were literate as compared to other clients $(P=0.001)$. Similarly, a higher proportion of truckers were currently married living with partners compared to clients in other professions $(P=0.003)$.

\subsection{Sexual Behavior}

Table 2 shows the sexual behavior of clients by occupational groups. The mean age at first sex was 19 years and the mean age at first paid sex was 21 years. No significant difference was observed between trucker clients and clients of FSWs in other profession in terms of age at first sex $(P=0.14)$ and age at first paid sex $(P=0.97)$. A higher proportion of trucker clients compared to other occupational groups reported having 6 or more sexual encounters with FSWs in the past six months $(P=0.03)$. A lower proportion of trucker clients, compared to other occupational groups, reported sex with men/transgender partners people in the past six months $(P=0.05)$. A 
Table 1. Social-demographic characteristics of clients of FSWs by occupational groups.

\begin{tabular}{|c|c|c|c|c|c|c|}
\hline \multirow[b]{2}{*}{ Socio-demographic characteristic } & \multicolumn{6}{|c|}{ Occupational groups } \\
\hline & $\begin{array}{l}\text { Trucker } \\
\text { clients } \\
(\mathbf{N}=\mathbf{3 0 6})\end{array}$ & $\begin{array}{l}\text { Other transport } \\
\text { workers } \\
\text { (N = 344) }\end{array}$ & $\begin{array}{l}\text { Unskilled/ } \\
\text { semi-skilled men } \\
\text { (N = 2572) }\end{array}$ & $\begin{array}{l}\text { Remaining } \\
\text { clients } \\
(\mathrm{N}=\mathbf{1 5 9 9})\end{array}$ & $\begin{array}{c}\text { Total } \\
(\mathbf{N}=\mathbf{4 8 2 1})\end{array}$ & $P$ value \\
\hline \multicolumn{7}{|c|}{ Current age } \\
\hline Up to 24 & $23.4 \%$ & $26.4 \%$ & $32.4 \%$ & $35.6 \%$ & $32.4 \%$ & \\
\hline $25-34$ & $48.0 \%$ & $45.6 \%$ & $38.5 \%$ & $38.0 \%$ & $39.5 \%$ & 0.25 \\
\hline 35 or above & $28.5 \%$ & $28.1 \%$ & $29.1 \%$ & $26.4 \%$ & $28.1 \%$ & \\
\hline Mean (SD) & $30.3(7.6)$ & $29.9(7.4)$ & $30.0(8.4)$ & $29.5(8.6)$ & $29.8(8.3)$ & \\
\hline \multicolumn{7}{|c|}{ Literacy } \\
\hline Illiterate & $11.9 \%$ & $23.3 \%$ & $26.4 \%$ & $19.4 \%$ & $22.9 \%$ & 0.001 \\
\hline Literate & $88.1 \%$ & $76.7 \%$ & $73.6 \%$ & $80.7 \%$ & $77.1 \%$ & \\
\hline \multicolumn{7}{|c|}{ Sexual partnership } \\
\hline Currently married-living with partner & $62.1 \%$ & $56.3 \%$ & $44.2 \%$ & $42.1 \%$ & $45.5 \%$ & \\
\hline Currently married-living along & $5.2 \%$ & $9.6 \%$ & $10.1 \%$ & $4.9 \%$ & $8.0 \%$ & 0.003 \\
\hline Not currently married-living with partner & $7.0 \%$ & $6.0 \%$ & $9.7 \%$ & $11.2 \%$ & $9.7 \%$ & \\
\hline Not currently married-living alone & $25.6 \%$ & $28.1 \%$ & $36.0 \%$ & $41.9 \%$ & $36.7 \%$ & \\
\hline
\end{tabular}

$P<0.05$; N-Total number of cases in the group; SD: Standard Deviation. Differences between the categories were tested by using Chi-square test.

significant difference was observed among respondents by occupation with regard to having regular female partner $(P=0.01)$.

\subsection{Prevalence of HIV/STI}

Table 3 presents HIV and STI prevalence among clients by occupational group. It is evident that other than $C$. trachomatis $(P=0.04)$, there was no significant difference in the prevalence of HIV $(P=0.42)$, Syphilis $(P=$ $0.63), N$. gonorrhea $(P=0.14)$, and any STI $(P=0.42)$ across the occupational groups.

\subsection{Association between Clients' Occupation and Sexual Risk Behavior and HIV/STI}

Table 4 represents results of the multivariate logistic regression models to estimated adjusted odds ratios. Results indicate that there was no significant difference between truckers and other clients in terms of the HIV and STI status and consistent condom use with FSWs.

\section{Discussion}

The study findings indicate that there is no significant difference in the sexual behaviors and prevalence of HIV and STI across the occupational groups of clients. The results also show that truckers constitute only a small fraction of the client's population and hence, contribution of truckers to HIV epidemic in India is likely to be smaller than the clients from occupational groups. The socio-demographic characteristics (age, literacy, and marital status) and sexual behavior of trucker clients (sexual partnerships and condom use) were consistent with the large-scale survey among truckers in India [5] [11] [18]. This supports the results obtained from this study by strengthening the belief that the survey represented client's population appropriately.

A large proportion of clients were constituted by semiskilled/unskilled labors who are mostly men from rural areas moved to cities for work. Such men return home after few months once they earned some money. Indian health experts call this phenomenon "the three Ms"-mobile men with money [20]. Men of this large peripatetic workforce are usually sexually active and are away from their family and regular sex partners for extended 
Table 2. Sexual behavior of clients by four occupational groups.

\begin{tabular}{|c|c|c|c|c|c|c|}
\hline \multirow[b]{2}{*}{ Sexual behavior } & \multicolumn{6}{|c|}{ Occupational Groups } \\
\hline & $\begin{array}{l}\text { Trucker } \\
\text { clients } \\
(\mathbf{N}=\mathbf{3 0 6})\end{array}$ & $\begin{array}{l}\text { Other transport } \\
\text { workers } \\
(\mathbf{N}=\mathbf{3 4 4})\end{array}$ & $\begin{array}{l}\text { Unskilled/ } \\
\text { semi-skilled men } \\
\text { (N = 2572) }\end{array}$ & $\begin{array}{l}\text { Remaining } \\
\text { clients } \\
(\mathbf{N}=\mathbf{1 5 9 9})\end{array}$ & 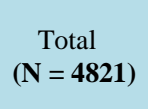 & $P$ value \\
\hline \multicolumn{7}{|c|}{ Age at first sex } \\
\hline Up to 18 & $59.4 \%$ & $42.0 \%$ & $45.7 \%$ & $45.8 \%$ & $46.3 \%$ & \multirow{3}{*}{0.14} \\
\hline 19 or above & $40.6 \%$ & $58.0 \%$ & $54.3 \%$ & $54.2 \%$ & $53.7 \%$ & \\
\hline Mean (SD) & $18.7(2.6)$ & $19.4(2.4)$ & $19.3(3.0)$ & $19.2(2.7)$ & $19.2(2.9)$ & \\
\hline \multicolumn{7}{|c|}{ Age at first paid sex with FSWs } \\
\hline Up to 18 & $23.3 \%$ & $24.9 \%$ & $25.1 \%$ & $25.5 \%$ & $25.2 \%$ & \multirow{3}{*}{0.97} \\
\hline 19 or above & $76.7 \%$ & $75.1 \%$ & $74.8 \%$ & $74.5 \%$ & $74.9 \%$ & \\
\hline Mean (SD) & $20.2(2.7)$ & $20.8(3.3)$ & $20.9(4.0)$ & $20.5(3.5)$ & $20.7(3.7)$ & \\
\hline \multicolumn{7}{|c|}{ Number of sexual encounters with FSWs in past 6 months } \\
\hline Up to 5 & $21.2 \%$ & $29.5 \%$ & $34.1 \%$ & $36.1 \%$ & $33.6 \%$ & \multirow{2}{*}{0.03} \\
\hline 6 or more & $78.8 \%$ & $70.5 \%$ & $65.9 \%$ & $63.9 \%$ & $66.4 \%$ & \\
\hline Mean (SD) & $8.2(6.4)$ & $5.0(3.5)$ & 6.4(5.4) & $5.7(5.5)$ & $6.2(5.4)$ & \\
\hline Consistent condom use with FSWs & $34.7 \%$ & $24.5 \%$ & $30.6 \%$ & $32.5 \%$ & $31.0 \%$ & 0.32 \\
\hline Ever had anal sex with FSWs & $13.7 \%$ & $18.8 \%$ & $15.2 \%$ & $16.3 \%$ & $15.7 \%$ & 0.80 \\
\hline Consistent condom use in anal sex with FSWs & $4.6 \%$ & $2.7 \%$ & $3.9 \%$ & $4.2 \%$ & $4.0 \%$ & 0.87 \\
\hline Ever had anal sex with other female partners & $7.3 \%$ & $13.5 \%$ & $7.8 \%$ & $11.6 \%$ & $9.5 \%$ & 0.23 \\
\hline $\begin{array}{l}\text { Consistent condom use in anal sex with } \\
\text { other female partners }\end{array}$ & $0.0 \%$ & $2.3 \%$ & $8.7 \%$ & $8.8 \%$ & $7.6 \%$ & 0.65 \\
\hline Had sex with men/transgender in past 6 month & $6.4 \%$ & $7.4 \%$ & $8.6 \%$ & $13.2 \%$ & $9.9 \%$ & 0.05 \\
\hline $\begin{array}{l}\text { Consistent condom use in anal sex with } \\
\text { male/transgender partner }\end{array}$ & $0.7 \%$ & $0.7 \%$ & $1.7 \%$ & $3.0 \%$ & $2.0 \%$ & 0.17 \\
\hline Had regular female partner & $61.6 \%$ & $77.5 \%$ & $58.7 \%$ & $61.5 \%$ & $61.2 \%$ & 0.01 \\
\hline Consistent condom use with regular female partner & $3.6 \%$ & $0.4 \%$ & $3.7 \%$ & $3.4 \%$ & $3.4 \%$ & 0.36 \\
\hline
\end{tabular}

$P<0.05$; N: Total number of cases in the group. Differences between the categories were tested by using Chi-square test.

Table 3. Prevalence of HIV and sexually transmitted infections among clients of female sex workers by occupational groups.

\begin{tabular}{|c|c|c|c|c|c|c|}
\hline \multirow{2}{*}{$\begin{array}{l}\text { Prevalence of } \\
\text { HIV and STI }\end{array}$} & \multicolumn{6}{|c|}{ Occupational groups } \\
\hline & $\begin{array}{l}\text { Trucker clients } \\
\qquad(\mathbf{N}=\mathbf{3 0 6})\end{array}$ & $\begin{array}{l}\text { Other transport workers } \\
\qquad(\mathbf{N}=\mathbf{3 4 4})\end{array}$ & $\begin{array}{l}\text { Unskilled/semi-skilled men } \\
\qquad(\mathbf{N}=\mathbf{2 5 7 2})\end{array}$ & $\begin{array}{l}\text { Remaining clients } \\
\quad(\mathbf{N}=\mathbf{1 5 9 9})\end{array}$ & 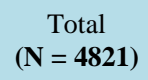 & $P$ value \\
\hline HIV & $8.2 \%$ & $4.9 \%$ & $7.7 \%$ & $5.5 \%$ & $6.8 \%$ & 0.42 \\
\hline Syphilis & $4.0 \%$ & $3.3 \%$ & $4.5 \%$ & $5.4 \%$ & $4.7 \%$ & 0.63 \\
\hline N. gonorrhoea & $0.0 \%$ & $1.4 \%$ & $0.4 \%$ & $0.4 \%$ & $0.4 \%$ & 0.14 \\
\hline C. trachomatis & $0.3 \%$ & $1.1 \%$ & $2.3 \%$ & $3.4 \%$ & $2.5 \%$ & 0.04 \\
\hline Any STI ${ }^{*}$ & $4.3 \%$ & $5.8 \%$ & $7.1 \%$ & $8.4 \%$ & $7.2 \%$ & 0.42 \\
\hline
\end{tabular}

$P<0.05$; N: Total number of cases in the group. Differences between the categories were tested by using Chi-square test. 
Table 4. Association between clients’ occupation and sexual risk behavior and HIV/STI Status.

\begin{tabular}{|c|c|c|c|}
\hline \multirow{2}{*}{ Occupational groups } & HIV & Any STI & Consistent condom use with FSWs \\
\hline & Adjusted OR (95\% CI) & Adjusted OR (95\% CI) & Adjusted OR (95\% CI) \\
\hline Trucker clients & Ref & Ref & Ref \\
\hline Other transport workers & $0.5(0.2-1.2)$ & $1.3(0.5-3.3)$ & $0.6(0.4-1.1)$ \\
\hline Unskilled/semi-skilled men & $0.7(0.3-1.7)$ & $1.6(0.7-3.6)$ & $0.9(0.6-1.4)$ \\
\hline Remaining clients & $0.6(0.2-1.4)$ & $2.1(0.8-5.2)$ & $0.9(0.6-1.4)$ \\
\hline
\end{tabular}

OR: Odds Ratios; 95\% CI: 95\% Confidence Interval; Ref: Reference category. Adjusted OR were estimated using multivariate logistic regression models.

periods of time. Thus, with sexual behaviors and prevalence of HIV and STI similar to those of truckers, these men appear to be contributing substantially to the India HIV epidemic. The high-risk sexual behaviors of migrant workers from low HIV prevalence areas to high HIV prevalence areas have also been documented [17] [21] [22]. Findings of the study reveals the fact truckers might be over-stigmatized for fueling the HIV epidemic in India [20].

We, however, do not intend to mean that truckers are at low risk of HIV and hence, the HIV prevention programs among truckers should continue to prevent new HIV infections. In fact, slightly higher HIV prevalence among trucker clients is an indication that in past truckers may have had riskier behaviors than other clients. This might be one of the reasons for truckers being the focus of intervention programs. However, being perceived as bridge populations and targeted by AIDS control programs for many years, stigmatization among truckers may result into other challenges for the program, such as disclosure of HIV status.HIV related stigma and discrimination have been shown to impede progress of intervention programs [23]. Studies from southern Brazil also indicates that stigma is an important barrier to HIV testing and disclosure among truck drivers [24].

The HIV program in the country emphasizes halting and reversing the epidemic, and it is necessary to examine whether the groups that are considered to be at higher risk of HIV and contributing more to the spread of the epidemic than others for strategic planning and programming. The evidences from the present study indicate that clients' population is constituted by many sub-groups and truckers only represent a small proportion of it. Further, the sexual behaviors of truckers are similar to other larger sub-groups of clients' population. These evidences suggest that the contribution of truckers in HIV epidemic in India might to similar to other sub-groups of clients' population. Thus, truckers might have been over-stigmatized as HIV carriers in the country. However, there is no doubt that truckers constitute an extremely important target group for the HIV prevention programs and these efforts must be continued to prevent new HIV infections in the country.

\section{Acknowledgements}

Support for IBBA surveys was provided by the Bill \& Melinda Gates Foundation through Avahan, the India AIDS Initiative. The views expressed herein are those of the authors and do not necessarily reflect the official policy or position of the Bill \& Melinda Gates Foundation and Avahan.

\section{References}

[1] Jochelson, K., Mothibeli, M. and Leger, J.P. (1991) Human Immunodeficiency Virus and Migrant Labor in South Africa. International Journal of Health Services, 21, 157-173. http://dx.doi.org/10.2190/11UE-L88J-46HN-HR0K

[2] Weine, S.M. and Kashuba, A.B. (2012) Labor Migration and HIV Risk: A Systematic Review of the Literature. AIDS and Behavior, 16, 1605-1021.

[3] Lichtenstein, B., Hook 3rd, E.W., Grimley D.M., St Lawrence, J.S. and Bachmann, L.H. (2008) HIV Risk among Long-Haul Truckers in the USA. Culture, Health and Sexuality, 10, 43-56.

[4] Sahu, D., Pandey, A., Mishra, R.M., Saggurti, N., Setu, S. and Singh, I.R. (2014) An Appraisal of Sexual Behaviors, STI/HIV Prevalence, and HIV Prevention Programs among Truckers in India: A Critical Literature Review. World Journal of AIDS, 4, 206-218.

[5] Pandey, A., Mishra, R.M., Sahu, D., Benara, S.K., Sengupta, U., Paranjape, R.S., et al. (2011) Heading towards the 
Safer Highways: An Assessment of the Avahan Prevention Programme among Long Distance Truck Drivers in India. BMC Public Health, 11.

[6] Pandey, A., Benara, S.K., Roy, N., Sahu, D., Thomas, M., Joshi, D.K., et al. (2008) Risk Behaviour, Sexually Transmitted Infections and HIV among Long-Distance Truck Drivers: A Cross-Sectional Survey along National Highways in India. AIDS, 22, S81-S90.

[7] Lippman, S.A., Pulerwitz, J., Chinaglia, M., Hubbard, A., Reingold, A. and Diaz, J. (2007) Mobility and Its Liminal Context: Exploring Sexual Partnering among Truck Drivers crossing the Southern Brazilian border. Social Science Medicine, 65, 2464-2473.

[8] Laukamm-Josten, U., Mwizarubi, B.K., Outwater, A., Mwaijonga, C.L., Valadez, J.J., Nyamwaya, D., et al. (2000) Preventing HIV Infection through Peer Education and Condom Promotion among Truck Drivers and Their Sexual Partners in Tanzania, 1990-1993. AIDS Care, 12, 27-40.

[9] National AIDS Control Organization (2007) Targeted Intervention for Truckers: Operational Guidelines, NACP III.Ministry of Health \& Family Welfare, Government of India New Delhi.

[10] Chaturvedi, S., Singh, Z., Banerjee, A., Khera, A., Joshi, R.K. and Dhrubajyoti, D. (2006) Sexual Behaviour among Long Distance Truck Drivers. Indian Journal of Community Medicine, 31, 153-156.

[11] Dude, A., Oruganti, G., Kumar, V., Mayer, K.H., Yeldandi, V. and Schneider, J.A. (2009) HIV Infection, Genital Symptoms and Sexual Risk Behavior among Indian Truck Drivers from a Large Transportation Company in South India. Journal of Global Infectious Diseases, 1, 21-28. http://dx.doi.org/10.4103/0974-777X.52977

[12] Sanjeev, K., Garg, S.K. and Bajpai, S.K. (2009) A Study of Knowledge, Sexual Behaviour and Practices Regarding HIV/AIDS among Long Distance Truck Drivers. Indian Journal of Public Health, 53, 243-245.

[13] Rao, K.S. (2009) Towards Containing HIV/AIDS Epidemic in India: Policies and Priorities under National AIDS Control Programme Phase-III (2007-12). Journal of Indian Medical Association, 107, 274-275.

[14] Bal, B., Ahmed, S.I., Mukherjee, R., Chakraborty, S., Niyogi, S.K., Talukder, A., et al. (2007) HIV Infection among Transport Workers Operating through Siliguri-Guwahati National Highway, India. Journal of the International Association of Physicians in AIDS Care, 6, 56-60. http://dx.doi.org/10.1177/1545109706298405

[15] Bill \& Melinda Gates Foundation (2008) Off the Beaten Track: Avahan’s Experience in the Business of HIV Prevention among India’s Long-Distance Truckers. Bill \& Melinda Gates Foundation, New Delhi.

[16] National AIDS Control Organization (2006) NACP-III-To Halt and Reverse the HIV Epidemic in India. Ministry of Health \& Family Welfare, Government of India, New Delhi.

[17] Chandrasekaran, P., Dallabetta, G., Loo, V., Rao, S., Gayle, H. and Alexander, A. (2006) Containing HIV/AIDS in India: The Unfinished Agenda. The Lancet Infectious Diseases, 6, 508-521. http://dx.doi.org/10.1016/S1473-3099(06)70551-5

[18] Pandey, A., Sahu, D., Mishra, R.M., Benara, S.K., Joshi, D.K., Sengupta, U., et al. (2008) Integrated Behavioral and Biological Assessment-National Highways: Survey Methodology and Implementation. Demography India, 37, 77-90.

[19] Saidel, T., Adhikary, R., Mainkar, M., Dale, J., Loo, V., Rahman, M., et al. (2008) Baseline Integrated Behavioural and Biological Assessment among Most At-Risk Populations in Six High-Prevalence States of India: Design and Implementation Challenges. AIDS, 22, S17-S34. http://dx.doi.org/10.1097/01.aids.0000343761.77702.04

[20] Mcdougall, D. (2005) Truckers Take India on Fast Lane to AIDS. http://www.theguardian.com/world/2005/nov/27/india.aids

[21] Saggurti, N., Nair, S., Malviya, A., Decker, M.R., Silverman, J.G. and Raj, A. (2012) Male Migration/Mobility and HIV among Married Couples: Cross-Sectional Analysis of Nationally Representative Data from India. AIDS and Behavior, 16, 1649-1658. http://dx.doi.org/10.1007/s10461-011-0022-z

[22] Saggurti, N., Verma, R.K., Jain, A., Rama Rao, S., Kumar, K.A., Subbiah, A., et al. (2008) HIV Risk Behaviours among Contracted and Non-Contracted Male Migrant Workers in India: Potential Role of Labour Contractors and Contractual Systems in HIV Prevention. AIDS, 22, S127-S136. http://dx.doi.org/10.1097/01.aids.0000343771.75023.cc

[23] Kinsler, J.J., Wong, M.D., Sayles, J.N., Davis, C. and Cunningham, W.E. (2007) The Effect of Perceived Stigma from a Health Care Provider on Access to Care among a Low-Income HIV-Positive Population. AIDS Patient Care and STDS, 21, 584-592. http://dx.doi.org/10.1089/apc.2006.0202

[24] Pulerwitz, J., Michaelis, A.P., Lippman, S.A., Chinaglia, M. and Diaz, J. (2008) HIV-Related Stigma, Service Utilization, and Status Disclosure among Truck Drivers Crossing the Southern Borders in Brazil. AIDS Care, 20, 764-770. http://dx.doi.org/10.1080/09540120701506796 